\title{
$t^{4}$ Workshop Report*
}

\section{Lessons Learned, Challenges, and Opportunities: The U.S. Endocrine Disruptor Screening Program}

Daland R. Juberg ${ }^{1}$, Susan J. Borghoff ${ }^{2}$, Richard A. Becker ${ }^{3}$, Warren Casey ${ }^{4 \S}$, Thomas Hartung ${ }^{5}$, Michael P. Holsapple ${ }^{6}$, M. Sue Marty ${ }^{7}$, Ellen M. Mihaich ${ }^{8}$, Glen Van Der Kraak ${ }^{9}$, Michael G. Wade ${ }^{10}$, Catherine E. Willett ${ }^{11}$, Melvin E. Andersen ${ }^{12}$, Christopher J. Borgert ${ }^{13}$, Katherine K. Coady ${ }^{7}$, Michael L. Dourson ${ }^{14}$, John R. Fowle III ${ }^{15}$, L. Earl Gray ${ }^{16 \dagger}$, James C. Lamb ${ }^{17}$, Lisa S. Ortego ${ }^{18}$, Thaddeus T. Schug ${ }^{48}$,Colleen M. Toole ${ }^{19}$, Leah M. Zorrilla ${ }^{20}$, Oliver L. Kroner ${ }^{14}$, Jacqueline Patterson ${ }^{14}$, Lori A. Rinckel ${ }^{20}$, and Brett R. Jones ${ }^{20}$

${ }^{1}$ Dow AgroSciences, Indianapolis, IN, USA; ${ }^{2}$ ToxStrategies Inc., Cary, NC, USA; ${ }^{3}$ American Chemistry Council, Washington, DC, USA; ${ }^{4}$ National Institute of Environmental Health Sciences, Research Triangle Park, NC, USA; Johns Hopkins University, Baltimore, MD, USA and University of Konstanz, Germany; ${ }^{6}$ Batelle, Columbus, OH, USA; 7 The Dow Chemical Company, Saginaw, MI, USA; ${ }^{8}$ ER2 and Endocrine Policy Forum, Durham, NC, USA; ${ }^{9}$ University of Guelph, Guelph, ON, Canada; ${ }^{10}$ Health Canada, Ottawa, ON, Canada; ${ }^{11}$ Humane Society of the United States, Washington, DC, USA; ${ }^{12}$ The Hamner Institutes for Health Sciences, Research Triangle Park, USA; ${ }^{13}$ Applied Pharmacology and Toxicology, Inc., Gainesville, FL, USA;

${ }^{14}$ Toxicology Excellence for Risk Assessment, Cincinnati, OH, USA; ${ }^{15}$ Science to Inform, Pittsboro, NC, USA; ${ }^{16}$ United States Environmental Protection Agency, Research Triangle Park, NC, USA; ${ }^{17}$ Exponent, Alexandria, VA, USA; ${ }^{18}$ Bayer CropScience, Raleigh-Durham, NC, USA; ${ }^{19}$ Ceetox, Kalamazoo, MI, USA; ${ }^{20}$ Integrated Laboratory Systems, Inc., Morrisville, NC, USA

\section{Summary}

In 1996, the U.S. Congress passed the Food Quality Protection Act and amended the Safe Drinking Water Act (SDWA) requiring the U.S. Environmental Protection Agency (EPA) to implement a screening program to investigate the potential of pesticide chemicals and drinking water contaminants to adversely affect endocrine pathways. Consequently, the EPA launched the Endocrine Disruptor Screening Program (EDSP) to develop and validate estrogen, androgen, and thyroid (EAT) pathway screening assays and to produce standardized and harmonized test guidelines for regulatory application. In 2009, the EPA issued the first set of test orders for EDSP screening and a total of 50 pesticide actives and 2 inert ingredients have been evaluated using the battery of EDSP Tier 1 screening assays (i.e., five in vitro assays and six in vivo assays).

To provide a framework for retrospective analysis of the data generated and to collect the insight of multiple stakeholders involved in the testing, more than 240 scientists from government, industry, academia, and non-profit organizations recently participated in a workshop titled "Lessons Learned, Challenges,

http://dx.doi.org/10.14573/altex.1309171

General Disclaimer: This workshop was conceived and developed by multiple stakeholders from government, industry, academia, and non-profits and organized by Toxicology Excellence for Risk Assessment (TERA). The report is being published by $t^{4}-$ the transatlantic think tank for toxicology, a collaboration of the toxicologically oriented chairs in Baltimore, Konstanz, and Utrecht sponsored by the DoerenkampZbinden Foundation. The opinions expressed in this report are those of the participants as individuals and do not necessarily reflect the opinions of the organizations they are affiliated with; participants do not necessarily endorse all recommendations made.

Additional Disclaimers:

$\S$ This manuscript is in part a work product supported by the National Institute of Environmental Health Sciences (NIEHS), National Institutes of Health (NIH), however the statements, opinions or conclusions contained therein do not necessarily represent the statements, opinions or conclusions of $\mathrm{NCI}$, NIEHS, NIH, or the United States government.

$\dagger$ The views expressed in this report are those of the individual authors and do not necessarily reflect the views and policies of the U.S. Environmental Protection Agency. 
and Opportunities: The U.S. Endocrine Disruptor Screening Program." The workshop focused on the science and experience to date and was organized into three focal sessions: (a) Performance of the EDSP Tier 1 Screening Assays for Estrogen, Androgen, and Thyroid Pathways; (b) Practical Applications of Tier 1 Data; and (c) Indications and Opportunities for Future Endocrine Testing. A number of key findings and recommendations related to future EDSP evaluations emanated from the collective sessions.

Keywords: endocrine disruptors, Tier 1, screening, systematic review, Endocrine Disruptor Screening Program

\section{Executive summary}

In response to public and scientific concern that various environmental chemicals may interfere with endocrine function in humans and wildlife, in 1996, the U.S. Congress passed the Food Quality Protection Act (FQPA) and amended the Safe Drinking Water Act (SDWA) requiring the U.S. Environmental Protection Agency (EPA) to implement a screening program to investigate the potential of pesticide chemicals and drinking water contaminants to adversely affect endocrine pathways. Consequently, the EPA launched the Endocrine Disruptor Screening Program (EDSP) and invested considerable time and effort over a number of years to develop and validate estrogen, androgen, and thyroid (EAT) pathway screening assays and to produce standardized and harmonized test guidelines for regulatory application. In 2009, the EPA issued the first set of test orders for EDSP screening and a total of 50 pesticide actives and 2 inert ingredients have been evaluated using the battery of EDSP Tier 1 screening assays (i.e., five in vitro assays and six in vivo assays) and the data submitted for review by EPA. In June 2013, EPA announced the second set of substances for EDSP Tier 1 screening, consisting of 41 pesticide active ingredients and 68 chemicals identified under the SDWA.

In order to provide a framework for retrospective analysis of the data generated and to collect the insights of multiple stakeholders involved in the testing, more than 240 scientists from government, industry, academia, and non-profit organizations participated in a workshop on the EDSP in April 2013. The workshop focused on the science and experience to date with the EDSP and identified opportunities to inform ongoing and future efforts to evaluate the endocrine disruption potential of chemicals. The workshop included presentations from invited speakers across three sessions, with each session followed by panel/ audience participation and additional invited experts serving as discussants. A number of key points and recommendations emanated from the collective sessions and are summarized below.

\section{Performance of the EDSP Tier 1 screening assays for estrogen, androgen, and thyroid pathways}

- Challenges in conducting the in vitro assays were identified and modifications that have been implemented by laboratories were shown to confer significant improvement in performance.

- Tier 1 in vivo mammalian assays have generally provided relevant information for informing on EAT activity, although several technical and interpretive challenges have been encountered in both the Hershberger and pubertal assays.
- A number of technical challenges have been encountered in the two non-mammalian screening assays and resolution of these challenges will improve future utility of generated data.

- The data generated from the Tier 1 screening assays are not appropriate to use in isolation for risk assessment purposes owing to the inability to adequately inform on adversity of effect, dose-response, and relevance to human exposure, although in some cases, these data may be used in conjunction with other toxicity data during the risk assessment process.

- Results from high concentrations/doses may overwhelm normal physiological function, and such data should be evaluated for biological significance to determine if they are scientifically relevant for use in screening for the potential to disrupt the endocrine system.

\section{Practical application of Tier 1 data}

- A systematic and transparent weight-of-evidence approach, incorporating dose-response data, other scientifically relevant information (OSRI) and mode(s) of action data (MOA) (when available), can inform decisions related to interpretation of Tier 1 data and whether Tier 2 testing is needed.

- A logic-based decision tree strategy for staging the EDSP Tier 1 screening assays may permit the attenuation of the EDSP and allow "gatekeeper" assays to inform subsequent testing requirements.

- Due to newness of the generated data to date and the challenge with interpretation of Tier 1 data, coupled with extensive animal use and cost of Tier 2 testing, a proposal for consideration of a Tier 1.5 approach that could include refined assessments and exploration of MOA should be considered.

- The selection of dose levels and exposure concentrations for the Tier 1 assays was a focal area of discussion that should be given increased attention in future screening.

- The assessment and application of alternative test data (e.g., ToxCast ${ }^{\mathrm{TM}}$, adverse outcome pathway data) could be useful in replacing Tier 1 screening assays provided that sufficient scientific validation of alternative approaches has been achieved for use in regulatory decision-making.

\section{Indications and opportunities for future endocrine testing}

- The EPA's vision for the EDSP - $21^{\text {st }}$ Century (EDSP21) focuses on utilization of high throughput screening (HTS) assays and computational modeling to prioritize chemicals 
for the EDSP, and, over a longer-time period, replace Tier 1 screening (U.S. EPA, 2011a).

- A framework for a validation strategy that would provide the evidence required for acceptance of HTS assays and prediction models for regulatory applications should be developed and reviewed by multiple stakeholders and independent reviewers for subsequent implementation.

- There are multiple centers of research that continue to advance thinking around potential for perturbation of endocrine pathways, including specific focal areas such as low-dose behavior, pathways of toxicity, and reverse toxicokinetics, all of which may inform Tier 1 screening data and beyond.

- Explicit consideration of human and ecological exposure potential could be valuable in future prioritization and decision making efforts.

- Current collaborations aimed at improvement of exposure assessment and reverse dosimetry screening with HTS data offer promise for developing a risk-based decision tool which could initially be used for priority setting and eventually for risk assessment purposes.

- Collaboration, coordination, and communication among the regulatory community and stakeholders are vital to insuring future scientific relevance and success of the EDSP program for informing on endocrine potential and for protection of human health and the environment.

\section{Introduction}

In response to public and scientific concern that various environmental chemicals may interfere with endocrine function in humans and wildlife, the U.S. Congress in 1996 passed the Food Quality Protection Act (FQPA) and amended the Safe Drinking Water Act (SDWA), which authorized the U.S. Environmental Protection Agency (EPA) to implement a screening program to investigate the potential of pesticides and drinking water contaminants to adversely affect some endocrine pathways (U.S. EPA, 1996a,b). Following an extensive review of the issues related to endocrine screening and testing by a formal advisory committee, the EPA launched the Endocrine Disruptor Screening Program (EDSP). The EPA, in collaboration with the Organisation for Economic Co-operation and Development (OECD), invested considerable time and effort over a number of years to develop and validate the necessary estrogen, androgen, and thyroid (EAT) pathway screening tests and to produce standardized and validated test guidelines for regulatory application. ${ }^{1}$

In 2009, the EPA issued the first set of test orders for EDSP screening of pesticide chemicals (i.e., both active ingredients and inerts). A total of 50 pesticide actives and 2 inert ingredients were recently evaluated using some or all of the battery of EDSP Tier 1 screening assays (i.e., five in vitro assays, four in vivo mammalian assays, and two in vivo non-mammalian assays) and the data were submitted to the EPA for review. The initial screening yielded large volumes of data derived from numerous

\footnotetext{
1 http://www.epa.gov/endo/pubs/edspoverview/index.htm
}

laboratories on a variety of chemical classes. Furthermore, in a recent EDSP public document, the EPA estimated that approximately 10,000 unique chemicals could potentially fall within the screening and prioritization universe under the FQPA and SDWA authorities (U.S. EPA, 2012). Due to the large number of chemicals and the recognition that the EDSP battery of assays requires significant time and resources (estimates range up to one million U.S. dollars and over 500 animals per chemical) for Tier 1 screening (Willett et al., 2011; U.S. EPA, 2013), a public workshop was organized to discuss the latest findings and experiences with the EDSP to ensure that opportunities for improvement, efficiencies, and scientific advancement are considered and adopted as appropriate in future EDSP prioritization, screening, and testing. The workshop specifically focused upon the results from the initial phase of screening, since it represents the first comprehensive experience utilizing these assays individually and as a battery in a regulatory context. It was designed to focus on the science and experiences to date and was not intended to be a forum to discuss individual chemicals and their performance in the Tier 1 screens. The collective experience and insight of the practitioners and laboratories involved in conducting the screening provides an unprecedented opportunity to retrospectively discuss the lessons learned and challenges encountered in order to identify opportunities for program refinement and advancement.

The public workshop, titled "Lessons Learned, Challenges, and Opportunities: The U.S. Endocrine Disruptor Screening Program," was held at the North Carolina Biotechnology Center in Research Triangle Park, North Carolina, USA on April 23-24, 2013. The workshop was also offered as a free webinar broadcast in real time. The workshop was conceived, developed, and actively organized by a consortium of interested stakeholders representing research institutions, government, industry, academia, animal welfare groups, and non-profit organizations (see Tab. 1). Dr Daland Juberg (Dow AgroSciences) and Dr Susan Borghoff (Integrated Laboratory Systems (ILS), Inc.) co-chaired the organizing committee and workshop.

Tab. 1: EDSP Workshop Organizing Committee Members Affiliations are for identification purposes only.

- Daland Juberg, Dow AgroSciences, Co-Chair

- Susan Borghoff, Integrated Laboratory Systems, Co-Chair

- Richard Becker, American Chemistry Council (ACC)

- Warren Casey, National Institute of Environmental Health Sciences (NIEHS)

- Thomas Hartung, Center for Alternatives to Animal Testing (CAAT), Johns Hopkins University

- Michael Holsapple, Battelle Memorial Institute

- Sue Marty, The Dow Chemical Company

- Ellen Mihaich, Endocrine Policy Forum and Environmental and Regulatory Resources

- Glen Van Der Kraak, University of Guelph

- Michael Wade, Health Canada

- Catherine Willett, Humane Society of the United States 
The specific objectives of the workshop were to:

- Provide participants with knowledge gained and lessons learned, including assay performance, by laboratories and organizations that performed testing on the Tier 1 chemicals.

- Identify challenges and best practices in the technical and biological assessment of endocrine activity.

- Discuss insights on the challenges of integrating and interpreting the data collected from Tier 1 assays (e.g., weight of evidence approaches and signature patterns).

- Explore insights on biological mechanisms relevant to endocrine modulation and their application in assay result interpretation and decision-making.

- Engage perspectives from a range of stakeholders, including academia, government, industry, and non-government organizations on the future implementation, challenges, and opportunities regarding the screening and evaluation of potential endocrine active chemicals using $21^{\text {st }}$ century tools and methodologies.

The workshop was divided into four sessions: Session I: Performance of the EDSP Tier I Screening Assays, Insights from Conducting Assays for List 1 Chemicals; Session II: Practical Applications of Tier 1 Data; Session III: Considerations in the Future of Endocrine Testing; and Session IV: Participant Discussion. The first three sessions commenced with formal presentations, each followed by a panel/audience question and answer session with additional invited experts serving as discussants. The workshop concluded with a fourth open audience session to provide all participants an opportunity to present their perspectives or concerns regarding the future of the EDSP. The workshop program and presentations are available online at: http:// www.tera.org/peer/edsp/. Table 2 lists speakers, session chairs, and panel discussants.

Over 240 scientists from government, industry, academia, and non-profits attended the workshop, of which more than 140 sci- entists participated in person and over 100 remotely via webinar. It is hoped that the discussion and outcomes of the workshop will inform and support improvements in: 1) the Tier 1 screening assays; 2) the sequence and staging of Tier 1 assays and interpretation of the Tier 1 battery; and (3) advancing the design and implementation of high throughput and non-animal methods in the EDSP $-21^{\text {st }}$ Century (EDSP21) and Toxicity Testing in the $21^{\text {st }}$ Century (TT21C) efforts. This report summarizes the presentations and major themes of the discussions and comments. In presenting the participants' comments and opinions we have not attempted to identify who was speaking or assign attribution to any individual. The comments and recommendations should not be considered to necessarily reflect a consensus or agreement amongst those attending the workshop. In some instances, the comments summarized may be from a single individual, in other cases the text is a synthesis of the discussions or recommendations offered by a number of participants.

\section{Workshop Session I: Performance of the EDSP Tier 1 screening assays; insights from conducting assays for List 1 chemicals}

\subsection{Plenary presentations}

This session focused on the conduct and performance of the eleven EDSP Tier 1 screening assays (see Tab. 3), highlighting specific challenges and recommended solutions based on their individual experiences to date. Three invited experts from laboratories involved in conducting the assays presented their experiences and discussed ideas for improving future EDSP testing. They also addressed the interpretation of individual assays with an emphasis on the challenges of interpreting apical assays and on achieving performance criteria.

Tab. 2: The four sessions of the workshop on Lessons Learned, Challenges, and Opportunities: The U.S. Endocrine Disruptor Screening Program*, listing session chairs, presenters, and discussants

\author{
Session I: Performance of EDSP Tier 1 Screening Assays \\ Session Chair: Susan Borghoff (ILS) \\ Presenters: Colleen Toole (Ceetox), Leah Zorrilla (ILS), Katherine Coady (Dow Chemical) \\ Panel Discussants: Ronald Biever (Smithers Viscient), Donald Stump (WIL Research), Kun (Sue) Yi (Syngenta) \\ Session II: Practical Applications of Tier 1 Data \\ Session Chair: Sue Marty (Dow Chemical) \\ Presenters: Earl Gray (EPA), Sue Marty (Dow Chemical), Christopher Borgert (APT) \\ Panel Discussants: Kevin Crofton (EPA), Ellen Mihaich (ER2), Patricia Bishop (PETA)

\section{Session III: Considerations for Future Endocrine Testing} \\ Session Chairs: John R. Fowle III (EPA, retired), Richard Becker (ACC), Warren Casey (NIEHS) \\ Presenters: David Dix ( EPA), Melvin Andersen (Hamner Institutes), Thomas Hartung (CAAT), Catherine Willett (Humane Society \\ USA), Lisa Ortego (Bayer CropScience), Thaddeus Schug (NIEHS)
}

Session IV: Open Discussion (James Lamb [Exponent], Michael Dourson [TERA], session chairs)

\footnotetext{
* The complete workshop agenda, including introductory and concluding presentations, is available online at http://tera.org/peer/edsp/
} 
The opening presentation by Dr Colleen Toole (CeeTox Laboratories) entitled "Review of In Vitro Assays - Validation Results and Methods for Improving In Vitro Tier 1 Endocrine Disruption Screening Assays" provided an overview of: 1) the five in vitro Tier 1 assays (see Tab. 3); 2) achieving the performance criteria for the in vitro assays; and 3) the challenges in conducting these assays. The presentation also discussed specific technical modifications that can be implemented for the successful conduct of each assay while still adhering to the EPA Office of Chemical Safety and Pollution Prevention (OCSPP) guidelines that resulted in significant improvements in screening assay performance.

The ERTA (Estrogen Receptor Transactivation Assay, see Tab. 3) measures luminescence produced by binding of a ligand to the estrogen receptor (ER) with subsequent transcription of a luciferase reporter gene. Overall, the performance criteria outlined in the EPA guideline for the four reference chemicals were met except with the weak positive, $17 \alpha$-methyl testosterone $(17 \alpha \mathrm{MT})$. Dr Toole recommended that evaluating a strong antagonist such as, ICI 182,780 in the ERTA assay would help in assay interpretation because it blocks specific ER-mediated responses allowing the identification of non-specific (i.e., non$h E R \alpha$-mediated) induction of the luciferase gene. This approach significantly reduces the potential false positive results. Additional modifications for the ERTA include alterations in the plate format to eliminate the edge effect and increasing the number of replicates ( 3 to 6 per concentration) to account for variability in the response.

In general, both the ER and androgen receptor (AR) (see Tab. 3 ) binding assays performed reasonably well as designed with the performance criteria outlined in the guidelines. These assays have been used for decades and are considered to be the "gold standard" for identifying substances that bind to either the ER or AR. However, a few challenges exist for both assays. First, when a test substance is identified to potentially interact with one of these receptors, secondary experiments should be conducted to determine if the interaction of the chemical with the receptor is a potential false positive (Laws et al., 2006). Another challenge for both of these assays is the use of rat uterine cytosol and rat prostate cytosol for the ER and AR assays, respectively. Using rat tissue cytosol as a source of receptor for both assays increases the use of animals and the need to characterize each preparation prior to use in the assay. Also, the volumes of solutions and different buffers used in the ER and AR assays create laboratory inefficiencies and, for the AR binding assay, two thirds of the cytosol preparation are not used in the assay and are subsequently discarded. Dr Toole suggested that EPA accept modifications in these assays when proficiency can be demonstrated with reference compounds.

The steroidogenesis assay (see Tab. 3) is designed to evaluate chemicals that affect the steroidogenesis pathway by evaluating statistically significant increases or decreases in estradiol and testosterone. This assay uses the H295R cell line. One of the challenges associated with this assay was the concentration of 22R-hydroxycholesterol (22RCH) recommended in the guidelines to increase basal levels of estradiol. Dr Toole stated that $40 \mu \mathrm{M}$ of $22 \mathrm{RHC}$ significantly decreases cell viability and suggested that the guideline be modified with this information.
Dr Toole modified the plate format from 24- to 48-well plates, thereby increasing the number of replicates per exposure concentration (3 to 6) and allowing identification of outliers in testosterone and estradiol levels.

The purpose of the aromatase assay (see Tab. 3) is to evaluate chemicals that inhibit the ability of CYP19 to convert androgen to estrogen using human recombinant microsomes as the source of aromatase. Although the aromatase assay performed reasonably well within the performance criteria outlined in the guidelines, the assay is performed in test tubes (not plate based), making it labor and time intensive. Dr Toole proposed miniaturizing the assay to decrease time and resources.

In summary, Dr Toole noted that the in vitro assays performed reasonably well. She recommended that there should be a reevaluation of the reference control data from all laboratories that conducted these assays and that these datat should be used to update the performance criteria in the OCSPP guidelines.

The second presentation was given by Dr Leah Zorrilla (ILS, Inc.) and entitled "Review of in vivo Mammalian Assays - Challenges and Considerations for Conducting and Interpreting these Screening Assays." Dr Zorrilla reviewed the four in vivo mammalian Tier 1 assays (see Tab. 3) regarding: 1) dose selection; 2) study conduct and performance criteria; and 3) challenges and solutions encountered. A positive aspect of using in vivo models is that they incorporate absorption, distribution, metabolism, and excretion of test substances, including evaluation of the metabolites as well as the parent substance. The pubertal assays were optimized to screen for the impact of disrupting the estrogen, androgen, and/or thyroid pathways on the developing endocrine system during pubertal maturation. The uterotrophic assay screens for potential estrogenic activity and can be performed in immature intact females or ovariectomized adult rats. The Hershberger bioassay is conducted to screen for both potential androgenic and anti-androgenic activity in the adult male castrated rat. Redundant endpoints are evaluated across these assays (e.g., tissue weights, hormones, and histopathology) and can provide information to inform about mode of action (MOA).

Dr Zorrilla noted that the uterotrophic and Hershberger assays were straightforward to conduct with relatively few challenges. For the uterotrophic assay, laboratories had little difficulty conducting or interpreting these data. A majority of uterotrophic assays conducted involved oral administration of the test substance to ovariectomized adult animals. Dr Zorrilla mentioned that caution should be taken when interpreting the results from a Hershberger assay if the test substance is a hepatic enzyme inducer. Administration of exogenous testosterone to a castrated animal when there is increased metabolic capability could increase testosterone metabolism, resulting in less testosterone available to maintain accessory sex tissue weights. This could then result in a decrease in organ weights because the animals are unable to synthesize more testosterone in response to the enhanced metabolism. Thus, compounds that enhance testosterone metabolism/clearance can yield an antiandrogenic response in the Hershberger assay and therefore this MOA may be misclassified as interaction with the androgen receptor or $5 \alpha$-reductase inhibition (Freyberger et al., 2007; Marty, 2013). 
Tab. 3: The EDSP Tier 1 screening battery

\begin{tabular}{|c|c|c|}
\hline Test & $\begin{array}{l}\text { OCSPP Harmonized } \\
\text { Test Guidelines }^{1}\end{array}$ & Intended Purpose of the Screening Assay \\
\hline \multicolumn{3}{|l|}{ In vitro } \\
\hline $\begin{array}{l}\text { Steroidogenesis (human } \\
\text { cell line - H295R) }\end{array}$ & 890.1550 & $\begin{array}{l}\text { To identify chemicals that affect the synthesis of sex steroid hormones } \\
\text { (e.g., estradiol/estrone and testosterone) }\end{array}$ \\
\hline $\begin{array}{l}\text { Aromatase (human } \\
\text { recombinant microsomes) }\end{array}$ & 890.1200 & $\begin{array}{l}\text { To identify chemicals that inhibit the catalytic activity of aromatase, } \\
\text { the enzyme responsible for the conversion of androgens to estrogens }\end{array}$ \\
\hline $\begin{array}{l}\text { Estrogen Receptor (ER) } \\
\text { binding (rat uterine cytosol) }\end{array}$ & 890.1250 & $\begin{array}{l}\text { To assess the ability of a chemical to interact with estrogen receptors (ERs) } \\
\text { isolated from rat uterus using a competitive binding assay }\end{array}$ \\
\hline $\begin{array}{l}\text { Androgen Receptor (AR) } \\
\text { binding (rat prostate cytosol) }\end{array}$ & 890.1150 & $\begin{array}{l}\text { To assess the ability of a chemical to compete with radiolabeled R1881 } \\
\text { (synthetic androgen) for binding in rat ventral prostate tissue homogenate }\end{array}$ \\
\hline $\begin{array}{l}\text { Estrogen receptor (ER) - } \\
\text { (hERa) transcriptional } \\
\text { activation (ERTA) - Human } \\
\text { cell line (HeLa-9903) }\end{array}$ & 890.1300 & $\begin{array}{l}\text { To assess the ability of a chemical to bind the ER and subsequently } \\
\text { transactivate an ER responsive element driven reporter gene demonstrating } \\
\text { an activation of an agonist response }\end{array}$ \\
\hline \multicolumn{3}{|l|}{ In vivo } \\
\hline Hershberger (rat) & 890.1400 & $\begin{array}{l}\text { To screen for potential androgen agonists, androgen antagonists, and } \\
5 \text { a-reductase inhibitors using a short term in vivo assay that measures } \\
\text { accessory sex tissue weights in castrated male rats }\end{array}$ \\
\hline Uterotrophic (rat) & 890.1600 & $\begin{array}{l}\text { To screen for potential estrogenic chemicals using a short-term in vivo } \\
\text { assay that measures uterine weights in ovariectomized adult or female } \\
\text { immature rats }\end{array}$ \\
\hline Pubertal male (rat) & 890.1500 & $\begin{array}{l}\text { To detect test substances with androgenic/antiandrogenic or antithyroid } \\
\text { activity, or which alter steroidogenesis or hypothalamic-pituitary-gonadal } \\
\text { function by examining puberty onset, organ weights (reproductive, accessory } \\
\text { sex tissues, and thyroid), histopathology (reproductive organs and thyroid) } \\
\text { and serum hormone levels (testosterone, T4, and TSH) }\end{array}$ \\
\hline Pubertal female (rat) & 890.1450 & $\begin{array}{l}\text { To detect test substances that have estrogenic/antiestrogenic or antithyroid } \\
\text { activity, or which alter steroidogenesis or hypothalamic-pituitary-gonadal } \\
\text { function by examining puberty onset, estrous cyclicity, organ weights } \\
\text { (ovaries, uterus, thyroid), histopathology (reproductive organs and thyroid), } \\
\text { and serum hormone levels (T4 and TSH) }\end{array}$ \\
\hline $\begin{array}{l}\text { Amphibian metamorphosis } \\
\text { (frog) }\end{array}$ & 890.1100 & $\begin{array}{l}\text { To detect substances that may interfere with the normal function of } \\
\text { the hypothalamic-pituitary-thyroid (HPT) axis by examining the progression } \\
\text { of amphibian metamorphosis }\end{array}$ \\
\hline Fish short-term reproduction & 890.1350 & $\begin{array}{l}\text { To detect test substances that have estrogenic/antiestrogenic, or } \\
\text { androgenic/antiandrogenic activity, or which alter steroidogenesis, or } \\
\text { hypothalamic-pituitary-gonadal function in fish by evaluating reproductive } \\
\text { performance, secondary sex characteristics, gonadosomatic index, } \\
\text { gonadal histopathology and vitellogenin levels }\end{array}$ \\
\hline
\end{tabular}

1 OCSPP Harmonized Test Guidelines: http://www.epa.gov/ocspp/pubs/frs/publications/Test_Guidelines/series890.htm

In each of the four mammalian assays it was necessary to select a dose that approached, but did not exceed the maximum tolerated dose (MTD) as defined in the individual assay guidelines. Although there was an extensive set of data on the substances on the first list of chemicals screened in these assays, for many of these studies the substances were not administered by oral gavage or conducted using juvenile animals. This presented a significant challenge and resulted in the need for laboratories to conduct dose range-finding studies using animals of similar ages as required by the EDSP test guideline and dosing over a period of 1 to 2 weeks. Dose range-finding studies increased the number of laboratory animals ( $\sim 30$ rats) required per test substance and insured that the high dose selected approached, but did not exceed, the MTD, providing confidence that the assays would not need to be repeated. Unless there is an adequate existing data set on the substance containing dose levels from 
oral administration to juvenile animals, the recommendation at this time is to conduct these dose range-finding studies.

Although most of the performance criteria were met with ease in both the male and female pubertal assays, male kidney weight, adrenal weights, and male serum thyroid stimulating hormone (TSH) levels were consistently outside the limits of the performance criteria, as stated in the guidelines, across various testing laboratories. In addition, interpretation of changes in T4 and TSH levels without corresponding changes in thyroid weight or thyroid follicular cell height and colloid area proved to be challenging. Some of the changes in these hormone levels may be the result of hepatic enzyme induction, which can alter the clearance of these hormones. Although the liver weight is measured in the pubertal assays, it is optional in the Hershberger assay. One recommendation for both assays is to include liver weight and retain the liver, using preservation methods suitable for subsequent biochemical measurements, in case further analysis of hepatic enzyme induction is necessary to assist in interpreting putative anti-androgen effects in the Hershberger assay and putative thyroid antagonism in the pubertal assays.

Dr Zorrilla also proposed that it would be helpful for EPA to provide: 1) clarification on the statistical analyses for future test orders, specifically in the two pubertal assays where multiple statistical analyses are required on the same data; and 2) more specific guidance on interpretation of thyroid-related endpoints and histopathology of the thyroid and reproductive organs so that there is consistency in the evaluation of these endpoints.

Dr Katherine Coady (The Dow Chemical Company) in a presentation entitled "Review of Non-mammalian Assays Challenges and Potential Solutions for the Conduct and Interpretation of the Amphibian Metamorphosis Assay and the Fish Short Term Reproduction Assay" provided a detailed review of the performance of the two non-mammalian EDSP Tier 1 assays: the amphibian metamorphosis assay (AMA) and the fish short-term reproductive assay (FSTRA). The AMA is a 21-day aquatic exposure designed to assess potential endocrine activity in the hypothalamus-pituitary-thyroid axis of developing African clawed frogs, Xenopus laevis. The FSTRA is a 21-day aquatic exposure designed to assess potential endocrine activity in the hypothalamic-pituitary-gonadal axis of sexually mature fathead minnows, Pimephales promelas. Dr Coady noted a number of technical challenges during the conduct of the two in vivo screening assays, including: 1) ensuring a sufficient fish/tadpole supply and limiting the incidence of infection; 2) fecundity performance requirements; 3) selection of the most appropriate test concentrations for each assay; 4) difficulties in meeting performance criteria of $<20 \% \mathrm{CV}$ in mean measured concentrations of the test compound; and 5) interpretation of assay data (i.e., determining the specificity of apical endpoints). She recommended the collection and preservation of extra tissues from both assays for the potential to explore the MOA in the event of unexpected findings. For the FSTRA, this would involve the collection of: 1) fish brain for aromatase activity; 2) fish liver and kidney for histopathology, and 3) fish liver for quantification of select mRNA targets. For the AMA, this would involve the collection of: 1) hind limb tissue, brain, and liver for mRNA analyses; and 2) gonads, kidneys, and liver for histopathology. Dr Coady also recommended that thyroid histopathology be routinely conducted for the AMA as it appears to represent a sensitive and specific endpoint.

\subsection{Open discussion}

The opening plenary speaker presentations on the performance of the EDSP Tier 1 screening assays for List 1 chemicals provided a strong foundation for the panel discussion and audience participation session that directly followed. During the open forum, workshop participants identified several additional issues relevant to the conduct, efficiency, and interpretation of the current EDSP Tier 1 screening assays. Table 4 highlights individual assay challenges and solutions that were identified in this session.

The current Tier 1 battery of assays utilizes at least 500 animals, not counting animals ordered but not allocated on study and animals used in dose range-finding studies (Willett et al., 2011). Participants commented that the development and implementation (following suitable validation) of more modernized and effective prioritization procedures and screens could significantly reduce this number and should be considered as the program moves forward.

Tier 1 data are only to be used to determine if a compound has the potential to interact with the endocrine system and if the substance should be moved forward to Tier 2 testing. Although Tier 2 tests generate the primary data to be used in risk assessment, some of the participants voiced concerns about the potential use of EDSP Tier 1 screening data in this process. However, it was pointed out that the endpoints in Tier 1 screens are not designed for risk assessment (i.e., dose-response is not evaluated for all endpoints) and the EDSP envisions use of Tier 2 results for risk assessment purposes in conjunction with Tier 1 data as well as other relevant scientific information for riskbased decision-making. A number of participants spoke of the importance and usefulness of maximizing the current information that the screens provide in order that they may be utilized more effectively for the identification of a potential MOA to determine what specific Tier 2 tests will be needed for risk-based decision-making for a specific substance.

Test chemical solubility was identified as a significant issue during the conduct of these screening assays. For example, in the FSTRA and the AMA, a considerable challenge was observed in the delivery of test chemical in water, with some test chemicals requiring a period of two weeks to achieve normalized concentrations. In addition, test substance delivery via food was not recommended as a potential solution due to dosage quantification (i.e., it is hard to ensure the fish/tadpoles are receiving the required dose) and missing the more sensitive route of exposure via the gills. Insufficient amount of iodide in the water was raised as a potential factor that could negatively affect the performance of the AMA. Analytical methods to detect iodide in water were challenging for labs; however, the iodide concentration in Sera Micron ${ }^{\circledR}$, the recommended feed for the AMA, was found to be approximately $50 \mathrm{mg} / \mathrm{kg}$ in one lab. Due to the availability of iodide in the tadpole's 
Tab. 4: Challenges and solutions for each Tier I assay

\begin{tabular}{|c|c|c|}
\hline Assay & Challenges & Solution \\
\hline \multicolumn{3}{|l|}{ In vitro } \\
\hline \multirow[t]{2}{*}{$\begin{array}{l}\text { Steroidogenesis } \\
\text { (human cell line - H295R) }\end{array}$} & 1) QC plate pass/fail & $\begin{array}{l}\text { 1) } 96 \text {-well format where prochloraz and forskolin can be tested on } \\
\text { same plate as test article }\end{array}$ \\
\hline & 2) Concentration setting & $\begin{array}{l}\text { 2) Run a range-finding study prior to study to determine viability, } \\
\text { solubility issues. }\end{array}$ \\
\hline $\begin{array}{l}\text { Aromatase (human } \\
\text { recombinant microsomes) }\end{array}$ & Assay volume/test tubes & $\begin{array}{l}\text { Allow other formats and flexibility for running the assay providing } \\
\text { reference controls and performance criteria still fall within guidelines. }\end{array}$ \\
\hline \multirow[t]{3}{*}{$\begin{array}{l}\text { Estrogen receptor (ER) } \\
\text { binding (rat uterine cytosol) }\end{array}$} & $\begin{array}{l}\text { 1) Source of receptor } \\
\text { (recombinant) }\end{array}$ & $\begin{array}{l}\text { 1) Allow other sources for receptor (recombinant estrogen receptor) } \\
\text { providing reference controls and performance criteria still fall within } \\
\text { guidelines. }\end{array}$ \\
\hline & 2) Buffers and volumes & $\begin{array}{l}\text { 2) Allow other formats and flexibility for running the assay providing } \\
\text { reference controls and performance criteria still fall within guidelines. }\end{array}$ \\
\hline & 3) Additional studies & 3) Follow up Ki studies to determine false positives. \\
\hline \multirow[t]{2}{*}{$\begin{array}{l}\text { Androgen receptor (AR) } \\
\text { binding (rat prostate cytosol) }\end{array}$} & $\begin{array}{l}\text { 1) Source of receptor } \\
\text { (recombinant) }\end{array}$ & $\begin{array}{l}\text { 1) Allow other sources for receptor (recombinant androgen receptor) } \\
\text { providing reference controls and performance criteria still fall within } \\
\text { guidelines. }\end{array}$ \\
\hline & 2) Buffers and volumes & $\begin{array}{l}\text { 2) Allow other formats and flexibility for running the assay providing } \\
\text { reference controls and performance criteria still fall within guidelines. }\end{array}$ \\
\hline \multirow{2}{*}{$\begin{array}{l}\text { Estrogen receptor (ER) - } \\
\text { (hERa) transcriptional } \\
\text { activation (ERTA) - Human cell } \\
\text { line (HeLa-9903) }\end{array}$} & 1) Cell health & $\begin{array}{l}\text { 1) Plate HeLa- } 9903 \text { cells in } 96 \text {-well plates and increase } \\
\text { recovery time from } 3 \text { to } 24 \mathrm{~h} \text {. }\end{array}$ \\
\hline & 2) False positives & $\begin{array}{l}\text { 2) Addition of } \mathrm{ICI} 182,780 \text { to each concentration of test material to } \\
\text { assist in identification of potential false positives. Change plate } \\
\text { format to remove controls from periphery of plate. Increase replicates } \\
\text { from } 3 \text { to } 6 \text { to allow for outlier identification. }\end{array}$ \\
\hline \multicolumn{3}{|l|}{ In vivo } \\
\hline Hershberger (rat) & $\begin{array}{l}\text { Interpretation when test } \\
\text { substance is an hepatic } \\
\text { enzyme inducer }\end{array}$ & $\begin{array}{l}\text { Measure liver weight and retain liver for follow-up studies to aid in } \\
\text { interpretation when there is an antiandrogen effect. Measure serum } \\
\text { testosterone levels. }\end{array}$ \\
\hline Uterotrophic (rat) & No challenges identified & \\
\hline \multirow[t]{2}{*}{ Pubertal male (rat) } & $\begin{array}{l}\text { 1) Interpretation of thyroid } \\
\text { responses }\end{array}$ & $\begin{array}{l}\text { 1) Along with measuring liver weight, retain liver for follow-up } \\
\text { studies to aid in the interpretation when there are changes in thyroid } \\
\text { hormones only; request EPA guidance on interpretation of thyroid } \\
\text { effects. }\end{array}$ \\
\hline & 2) Statistical approaches & 2) Request EPA guidance on statistical approaches. \\
\hline \multirow[t]{2}{*}{ Pubertal female (rat) } & $\begin{array}{l}\text { 1) Interpretation of } \\
\text { thyroid responses }\end{array}$ & $\begin{array}{l}\text { 1) Along with measuring liver weight, retain liver for follow-up } \\
\text { studies to aid in the interpretation when there are changes in thyroid } \\
\text { hormones only; request EPA guidance on interpretation of thyroid } \\
\text { effects. }\end{array}$ \\
\hline & 2) Statistical approaches & 2) Request EPA guidance on statistical approaches. \\
\hline \multirow[t]{3}{*}{$\begin{array}{l}\text { Amphibian metamorphosis } \\
\text { (frog) }\end{array}$} & 1) Tadpole Supply & $\begin{array}{l}\text { 1) Additional breeding pairs may be needed to be able to set a study } \\
\text { along a prescribed timeline; it is important to control density and } \\
\text { food availability to ensure tadpoles develop accordingly. }\end{array}$ \\
\hline & 2) Concentration setting & $\begin{array}{l}\text { 2) Run a range-finding study (may need to be prolonged beyond } 96 \mathrm{~h} \text { ); } \\
0.1 \mathrm{x} \text { dose separation may be preferred to ensure two treatment levels } \\
\text { without overt toxicity. }\end{array}$ \\
\hline & $\begin{array}{l}\text { 3) Meeting performance } \\
\text { criteria of } \leq 20 \% \mathrm{CV} \text { in } \\
\text { mean measured } \\
\text { concentrations }\end{array}$ & $\begin{array}{l}\text { 3) Increase time of equilibration, increase turn-over rate, increase } \\
\text { analytical sampling and use time weighted means, use carrier } \\
\text { solvent (not preferred); increase stock solution delivery rate } \\
\text { (possibly not preferred); increase frequency of tank cleanings. }\end{array}$ \\
\hline
\end{tabular}




\begin{tabular}{|c|c|c|}
\hline Assay & Challenges & Solution \\
\hline \multicolumn{3}{|l|}{ In vivo } \\
\hline \multirow[t]{2}{*}{$\begin{array}{l}\text { Amphibian metamorphosis } \\
\text { (frog) }\end{array}$} & $\begin{array}{l}\text { 4) Significant number of } \\
\text { tadpoles progressing } \\
\text { beyond NF stage } 60\end{array}$ & $\begin{array}{l}\text { 4) Perform nested statistical analysis if }>20 \% \text { beyond NF stage } 60 \text {; } \\
\text { use early stage } 51 \text { to set a study; restrict feeding. }\end{array}$ \\
\hline & 5) Study interpretation & $\begin{array}{l}\text { 5) Collect additional tissues in case additional MOA information } \\
\text { is needed; recommend performing thyroid histopathology } \\
\text { regardless of other study endpoint results. }\end{array}$ \\
\hline \multirow[t]{5}{*}{ Fish short-term reproduction } & $\begin{array}{l}\text { 1) Sufficient fish supply } \\
\text { free of infection }\end{array}$ & $\begin{array}{l}\text { 1) Order additional fish; have several preferred suppliers and } \\
\text { an in-house stock of fish in case of infection, clean fish glassware } \\
\text { with a mycobacteriocide; pre-screen fish lots via histopathology } \\
\text { to check for signs of infection before using fish on a study. }\end{array}$ \\
\hline & $\begin{array}{l}\text { 2) Meeting fecundity } \\
\text { performance criteria }\end{array}$ & $\begin{array}{l}\text { 2) Use trays on the breeding platforms to catch eggs and } \\
\text { increase feeding regimen. }\end{array}$ \\
\hline & 3) Concentration setting & $\begin{array}{l}\text { 3) Run a range-finding study (may need to be prolonged beyond } 96 \mathrm{~h} \text { ); } \\
0.1 \mathrm{x} \text { dose separation may be preferred to ensure two treatment } \\
\text { levels without overt toxicity. }\end{array}$ \\
\hline & $\begin{array}{l}\text { 4) Meeting performance } \\
\text { criteria of } \leq 20 \% \mathrm{CV} \text { in } \\
\text { mean measured } \\
\text { concentrations }\end{array}$ & $\begin{array}{l}\text { 4) Increase time of equilibration, increase turn-over rate, increase } \\
\text { analytical sampling and use time weighted means, use carrier } \\
\text { solvent (not preferred); increase stock solution delivery } \\
\text { rate (possibly not preferred); increase frequency of tank cleanings. }\end{array}$ \\
\hline & 5) Study interpretation & $\begin{array}{l}\text { 5) Collect additional tissues in case additional MOA information is } \\
\text { needed. }\end{array}$ \\
\hline
\end{tabular}

diet, coupled with the fact that the control tadpoles in the AMA developed along expected timelines and generally met the guideline's developmental performance criteria, the amount of iodide in the water was not considered to significantly affect assay performance as iodide was demonstrably available in the tadpole feed.

There was much discussion about the AMA with concern expressed that it only evaluates the physiological effect of thyroid function. It was noted that equivalent information could be obtained from rat pubertal assays, which are considered to be, in general, more sensitive than the AMA. However, in the AMA and FSTRA, there is no first pass metabolism when exposure primarily occurs via the gills; thus, this may represent a unique exposure pathway not represented in the pubertal rat screening assays. The identification or assignment of a specific MOA in the AMA is challenging. For example, several instances of accelerated hind limb development were observed in the AMA which, according to the guidelines, is indicative of thyroid activity. However, for the majority of cases where accelerated hind limb development was observed there was also a lack of associated thyroid histopathology effects. Several participants noted that measurement of thyroid activity represents the most challenging pathway in the EDSP, with no resolution to this issue identified.

The selection of an appropriate maximum tolerated dose or concentration for conducting the in vivo assays was an issue discussed in much detail. There was general concern that systemic toxicity could affect a number of endpoints evaluated in these assays. The selection of an MTD for the high dose in these screening assays was a challenge due to the ability of these doses to indirectly induce a significant reproductive effect (e.g., cessation of spawning) during the FSTRA. A number of participants commented that further investigation and allocation of resources were needed to address the role of generalized stress and toxicity on the disruption of endocrine activity in the in vivo assays that use dose levels that compromise the physiological state of the animal.

Several additional technical challenges encountered during the conduct of the Tier 1 in vitro assays were discussed, including: 1) meeting reference chemical performance, especially for the very weak agonist, $17 \alpha$-methyltestosterone in the ERTA, 2) guideline constraints for ER and AR competitive binding assays which impact the efficiency of screening (e.g., if laboratories can demonstrate proficiency, allow for modifications in buffers, volumes used in assays, sources of receptors, and perhaps automation), and 3) modifications in the concentration of $22 \mathrm{RCH}$ used in the steroidogenesis assay.

Some participants questioned the requirement and value (i.e., biological significance) of conducting in vitro assays at high concentrations. It was noted that dose levels tested in cell-based assays need to generate data that are both scientifically relevant and meet EPA guidelines. Importantly as well, in vitro assays should include assessment of cytotoxicity, solubility, and other nonspecific in vitro effects that could confound interpretation of results, particularly at high concentrations. 


\section{Workshop Session II: Practical applications of Tier 1 data}

\subsection{Plenary presentations}

The second session focused on the use of relevant information from the current EDSP Tier 1 screening battery to inform: 1 ) how to stage Tier 1 screening assays in a more efficient manner; 2) how to use Tier 1 and OSRI to identify potential modes of action; and 3) how to incorporate available information into a weight of evidence (WOE) assessment for evaluating potential interactions with endocrine pathways. General principles of WOE and the EPA's WOE document for evaluating Tier 1 endocrine results were presented and an information framework was introduced that can be used for WOE assessments and/ or differentiating potential MOAs (Borgert et al., 2011b; U.S. EPA, 2011b).

Dr Earl Gray (EPA) in a presentation titled "A Two-TieredTesting Decision Tree for Assays in the USEPA-EDSP Screening Battery: Using 15 years of Experience to Improve Screening and Testing for Endocrine Active Chemicals" discussed an alternative logic-based decision-tree strategy for staging the EDSP Tier 1 screening assays (Ankley and Gray, 2013). The strategy involves utilizing two in vivo assays (e.g., FSTRA and the male rat pubertal assay) as "Gatekeepers." Using this proposed framework, if both assays yield negative results for potential endocrine activity, then a chemical would be considered a low priority for further endocrine evaluation and additional Tier 1 assays would not be conducted. Conversely, if the "gatekeeper" assays detected any positive results, then additional specific Tier 1 assays would be conducted on a case-by-case basis, depending upon the specific estrogen (E), androgen (A), or thyroid (T) signals observed in the two "gatekeeper" assays. This proposed alternative EDSP screening strategy was coined "Tier 0.5 " by workshop participants. Dr Gray also discussed the potential value of incorporating a possible "Tier 1.5" screening strategy in lieu of moving directly to Tier 2 for chemicals with positive Tier 1 results. He noted that the current challenges in interpreting Tier 1 data concern over-extensive animal use, and the significant costs of Tier 2 assays are compelling reasons for the potential implementation and use of this alternative screening approach. Briefly, Tier 1.5 could be conducted following Tier 1 screening, and utilize additional or refined in vitro or short-term in vivo assays to confirm equivocal Tier 1 screening results or explore potential effects and modes of action in more detail prior to the selection and initiation of extensive Tier 2 testing. He also cautioned against using pubertal male and female rat data to classify chemicals as potential endocrine disruptors (EDs) when the dosage levels produced overt toxicity or exceeded the MTD, since reduction in terminal body weights greater than $10 \%$ of control are clearly associated with reductions in several E, A and T-regulated endpoints (Laws et al., 2007). Dr Gray also noted that some of the endpoints sensitive to E and A are not included in multigenerational assays. These specific endpoints could be added on a case-by-case basis as indicated by the EDSP screening data. In addition, for some effects, the multigenerational assays do not examine a sufficient number of animals to detect the no observed adverse effect (NOAEL) accurately (Blystone et al., 2010).

Dr Sue Marty (The Dow Chemical Company) in a talk titled "Pulling it Together - Preparing for a Weight of Evidence Assessment on Endocrine Activity" provided a review of the value of using a transparent WOE and MOA assessment for Tier 1 EDSP screening data. She explained how a WOE approach similar to the approach described by the EPA (U.S. EPA, 2011b) could contribute a robust, scientific method to data evaluation and could provide enhanced confidence in decisions for Tier 2 testing. As part of the WOE assessment, the quality of the scientific information is examined and data are evaluated to determine the extent to which hypothetical effects on the estrogen, androgen and/or thyroid pathways are supported. The WOE assessment integrates information from the EDSP Tier 1 assays and OSRI and examines complementarity across Tier 1 assays, consistency in patterns of effects (including model, dose and duration), coherence across studies, and biological plausibility. Greater weight is given to in vivo results than in vitro findings. Dr Marty noted that EDSP Tier 1 assays were designed to minimize "false negative" results; therefore, implementation of a WOE approach with Tier 1 data could also confer improved data evaluation by examining patterns of effects across assays. This may provide some assurance of assay specificity (i.e., some control of the false positive rate) and, when appropriate, could provide a more informed approach to tailor Tier 2 testing. Dr Marty stated that a WOE assessment should incorporate Tier 1 EDSP results, as well as previous toxicity data (e.g., the extensive registration data sets required for pesticide active ingredients), and both ToxCast ${ }^{\mathrm{TM}}$ data and published literature (i.e., when deemed relevant and reliable). She discussed EPA's proposed signature Tier 1 assay responses (i.e., fingerprints) for compounds acting via different endocrine MOAs. She noted, however, that numerous scenarios are possible, whereby a chemical will not produce the full signature response as identified in the EPA WOE document (EPA, 2011b). Dr Marty stated that, based on a recent case study, it appears that compounds that induce liver enzymes and enhance steroid hormone clearance, a MOA that is not considered an endocrine disruptor MOA in the EDSP, can lead to responses in certain Tier 1 screens that would appear to be indicative of anti-androgenic or anti-thyroid activity.

Dr Christopher Borgert (APT, Inc.), in a presentation titled " $A$ Weight of Evidence Approach to Examine Endocrine Activity" provided information on a recently published hypothesis-based WOE framework that utilizes data from Tier 1 screening assays (Borgert et al., 2011a). The methodology is currently undergoing refinement to apply quantitative (relevance) weighting to each endocrine endpoint in the Tier 1 assays, depending on whether an endpoint is: 1) a primary indicator of endocrine activity (i.e., specific for an endocrine MOA hypothesis); 2) a secondary indicator of endocrine activity (responsive to the MOA, but not as specific); or 3 ) supportive data to be used in conjunction with other evidence. Using this approach, compounds that operate by a specific MOA should affect a number of primary endpoints indicative of this MOA; for example, if a compound is estrogenic through binding to the estrogen receptor, primary indica- 
tors of this MOA might include a positive uterotrophic assay or increased vitellogenin in male fish. Secondary and supportive endpoints would also be affected, for example, altered estrous cycle pattern/length or reproductive organ weights/histopathology in the female pubertal assay, or altered vitellogenin levels in females, decreased male tubercle scores, and altered reproductive organ histopathology in fish. Alterations in secondary endpoints are expected with this MOA, but are not diagnostic of estrogenicity. If primary endpoints specific for this MOA are not altered, the evidence for this MOA is tenuous. Thus, the relevance of each endpoint is assigned a weight according to its importance for evaluating a specific hypothesis (Borgert et al., 2011a, 2013). Dr Borgert explained that response weighting across various endocrine MOAs is employed in the WOE assessment, in which test chemical responses can be compared to the range of responses elicited by positive and negative control compounds. This proposed WOE approach for the EDSP is designed to be transparent, testable, objective, reproducible, updatable, and biologically plausible.

\subsection{Open discussion}

The second open discussion period expanded upon the plenary speaker presentations addressing the practical applications of EDSP Tier 1 data. A broad spectrum of testing strategies and approaches was identified and discussed by the panel discussants and workshop participants.

Exposure and dose were emphasized as two critical issues that should be given increased consideration for future Tier 1 screening programs and decisions regarding the progression to Tier 2 testing. Participants suggested that if the potential for human and wildlife exposure is only minimal, a subset of Tier 1 screening might be deemed appropriate (e.g., focus on mammalian assays and a dosing regimen relative to potential human exposures, and fish/amphibian assays and a dosing regimen for wildlife exposures) or additional Tier 2 testing might not be warranted.

The idea of incorporating a critical systematic evaluation of existing Tier 1 data and OSRI prior to the implementation of Tier 2 testing in multiple species was endorsed by many of those who spoke. This type of evaluation could identify issues related to complementarity and consistency that should be addressed prior to launching Tier 2 studies and/or enable the development of a modernized, tailored testing approach (e.g., identification of data gaps in Tier 1.5) for each chemical prior to any Tier 2 testing. Similarly, it was suggested that conducting a systematic review of the Tier 1 results for List 1 compounds prior to screening EDSP List 2 compounds could avoid costly and potentially unnecessary testing procedures.

Many participants commented positively on the proposed Tier 1.5 screening strategy described by Dr Gray. The potential adaptation of a tailored, purpose-fit approach was considered a desirable alternative strategy that could refine the currently sizable (and time-consuming) testing processes included in Tier 2. However, it was noted that while EPA may be amenable to tailored testing strategies, the incorporation of this alternative approach into existing guidelines and regulatory structures could be time-consuming.
Others thought that the implementation of additional tiers of testing (e.g., Tier 0.5 or Tier 1.5) would facilitate a more stringent evaluation of the data generated from the screening (Tier 1) assays. For example, conducting the assays in a particular order (e.g., initiate in vivo assays first, then follow up with in vitro assays as needed based on mechanistic signals) and staged over an appropriate period of time. This process could aid in making more informed decisions regarding the test chemicals.

The presentation by Dr Borgert of an alternative WOE approach for assessing endocrine activity generated engaged participant discussion. Some participants commented that it is a highly transparent, structured strategy that promotes the consistent facilitation of Tier 1 data. Several participants indicated that analysis of Tier 1 data utilizing this approach would greatly enhance decision making for Tier 2 testing. Finally, a decision matrix that all stakeholders can utilize to ultimately generate the same or consistent results was considered an important requirement going forward.

Concern regarding the absence of thyroid-sensitive endpoints in the current Tier 2 rat two-generation reproductive toxicity study (OCSPP 870.3800) was discussed and participants thought that a test measuring these endpoints was important. It was noted that the EPA has some latitude in the requirements for Tier 2 testing and, therefore, a pre-/postnatal thyroid assessment (U.S. EPA, 2005) could be required in Tier 2 for potential thyroid-active compounds. Alternatively, the extended one-generation reproductive toxicity study (EOGRTS), which includes thyroid evaluations, is an accepted Tier 2 test (OECD, 2012). Given the importance of thyroid hormone for brain development, further tests for thyroid activity may be warranted.

Several participants expressed concern regarding the upcoming progression from Tier 1 to Tier 2 testing for some List 1 chemicals and it was suggested that it might be worthwhile to consider how to incorporate exposure information into these decisions. This approach would provide a more relevant, tailored strategy for deciding which chemicals advance to Tier 2 testing. Recognizing the slow progress (and high cost) of the EDSP since its inception, an underlying objective expressed by many participants was the desire to have a more streamlined, cost-effective, and science-based approach for Tier 2 .

Several participants commented that the assessment and application of alternative methods that are frequently discussed these days (e.g., ToxCast ${ }^{\mathrm{TM}}$, Tox 21 , adverse outcome pathways) could eventually replace Tier 1 assays, provided scientific validation of alternative approaches has been achieved to inform regulatory decision-making. It was noted that there is a proposal to use ToxCast ${ }^{\mathrm{TM}}$ approaches (i.e., EDSP21) to prioritize compounds for EDSP Tier 1 screening of potential $\mathrm{E}, \mathrm{A}$, and $\mathrm{T}$ activities and, if possible, to eventually replace certain Tier 1 assays with ToxCast ${ }^{\mathrm{TM}}$ assays. Work towards these goals is ongoing and has been budgeted in the FY2014 EPA budget. If the validity and predictiveness of ToxCast ${ }^{\mathrm{TM}}$ is confirmed, ToxCast ${ }^{\mathrm{TM}}$ results may be used at some future date to focus further evaluation using a subset of Tier 1 EDSP assays based on pathway interactions or to replace Tier 1 assays entirely (EPA, 2011a). 


\section{Workshop Session III: Considerations in the future of endocrine testing}

In 2012 the EPA announced plans for an EDSP for the $21^{\text {st }}$ Century (EDSP21) that outlines a multi-year transition from the current EDSP Tier 1 screening battery and Tier 2 tests to a more efficient use of computational toxicology and HTS in vitro assays (EPA, 2011a). The initial goal of EDSP21 is to bring forward a rapid, biologically-based approach for EPA to use for prioritization of chemicals to enter into the EDSP. The ultimate objective is to replace some, if not all, of the existing EDSP assays and thereby significantly reduce animal use and economize on time and testing costs. The third session of the workshop provided perspectives on ways to improve the future of endocrine screening and the promise of in vitro high-throughput analyses and computational toxicology, toxicity pathways, and prediction models for this purpose. The promises, opportunities, challenges, and concerns associated with the tools and approaches to implement the NRC (2007) report, "Toxicity Testing in the $21^{\text {st }}$ Century: A Vision and a Strate$g y$," have been widely discussed and debated in recent years. One goal of this session was to provide some perspective on how the future of endocrine screening and testing is being shaped by the integration of new tools currently being developed.

\subsection{Plenary presentations}

Dr David Dix (EPA), in a presentation titled "EPA ToxCast HTS Assays and Prediction Models for Estrogen, Androgen, Thyroid and Steroidogenesis Pathways", commenced with a brief overview of current EPA activities pertaining to the EDSP. He noted that the EPA is currently:

1) Reviewing the Tier 1 results from the 52 substances that have competed EDSP Tier 1 screening and conducting WOE evaluations to determine potential interactions with endocrine systems and whether a chemical warrants further evaluation in specific Tier 2 tests.

2) Finalizing the interlaboratory validation of Tier 2 test protocols to be used to determine adverse effects and dose response for risk assessment for those substances that warrant specific Tier 2 testing based on EDSP Tier 1 results.

3) In the process of finalizing a second list of substances to undergo EDSP Tier 1 screening; these substances were selected based on indications of presence in drinking water. EPA is finalizing procedures to begin issuing orders to conduct Tier 1 screening for these chemicals.

4) Working to bring forward and validate advanced approaches (ToxCast ${ }^{\mathrm{TM}}$ methods) to be used in future rounds of prioritization to select chemicals to undergo EDSP Tier 1 screening. Dr Dix described the coordinated collaboration currently underway between the EDSP and the EPA's Office of Research and Development to identify computational toxicology-based approaches for chemical prioritization, and to develop more efficient approaches for assessing a chemical's potential to interact with EAT and steroidogenesis systems. The EPA's ToxCast ${ }^{\mathrm{TM}}$ research project is currently utilizing rapid, automated methods (i.e., high-throughput screening [HTS] assays) and computational modeling to evaluate endocrine activity. Dr Dix discussed how ToxCast $^{\mathrm{TM}}$ chemical screening methods (and other HTS assays) might ultimately replace one or more of the current assays in the Tier 1 screening battery, and thereby increase the speed and efficiency of screening for potential endocrine activity, while significantly reducing animal use.

The Hamner Institutes is developing case study approaches using fit-for-purpose in vitro toxicity pathway assays as the basis for risk assessments (Bhattacharya et al., 2011). Dr Melvin Andersen, in a talk titled "Tier 1 and Done: Developing in vitro Cell-based Assays of Endocrine Pathways Sufficient by Themselves for $21^{\text {st }}$ Century Risk Assessment", provided an overview of promising research by the Hamner Institutes to design scientifically robust prediction models to elucidate dose-response behaviors at low, environmentally relevant levels of exposures that would be considered sufficient for safety assessments with estrogenic compounds without utilizing whole animal toxicity studies $^{2}$. He noted that the overall goal of this research program is to provide "validated" in vitro assays for estrogen pathways in human uterine cells through the utilization of molecular probes to elucidate pathway dynamics, cellular perturbations, and reverse toxicokinetics to predict regions of safety for exposures to specific compounds. Dr Andersen outlined ongoing research activities with Ishikawa cells, i.e., a human uterine adenocarcinoma cell line, including: 1) the enumeration of data streams to map the estrogen signaling pathway for compounds that selectively activate estrogen receptor (ESR) 1, ESR2, G proteincoupled estrogen receptor, and membrane forms of ESR1;2) analyses of the initial structure of the multi-receptor; 3 ) investigation of computational systems biology pathway models; and 4) analyses of risk/safety assessment directions provided by a detailed understanding of pathway architecture.

Dr Thomas Hartung (Johns Hopkins University and University of Konstanz), in a presentation titled "Mapping the $\mathrm{Hu}$ man Toxome by Systems Toxicology - Using ED as a Proof of Concept", provided information on a developing public database of pathways of toxicity to promote modern technologies to enable greater scientific collaboration and exchange. Termed the "Human Toxome", this comprehensive pathway list could also be incorporated with: 1) an annotation of cell types, species, toxicant classes, and hazards to these pathways; 2) information on systems toxicology approaches; and 3) an in vitro to in vivo extrapolation by reverse dosimetry. The Center for Alternatives to Animal Testing (CAAT) is directing the Human Toxome Project via funding from a transformative research grant from the National Institutes of Health. The project, which is currently utilizing pro-estrogenic endocrine disruption as its test case, involves a close collaboration with EPA ToxCast ${ }^{\mathrm{TM}}$, The Hamner Institutes, Agilent, and several other members of the Tox 21 panel $^{4}$.

\footnotetext{
2 http://www.thehamner.org/tt21c

3 http://humantoxome.com

4 The Toxicology in the $21^{\text {st }}$ Century (Tox21) program is a federal collaboration involving National Institutes of Health (NIH), Environmental Protection Agency (EPA), and Food and Drug Administration (FDA). This collaboration is aimed at developing better toxicity assessment methods to quickly and efficiently test whether certain chemical compounds have the potential to disrupt processes in the human body that may lead to adverse health effects.
} 
Dr Hartung also provided an overview of the "Pathways of Toxicity" research program at Johns Hopkins University and the Evidence-based Toxicology Collaboration (EBTC) ${ }^{5}$ The EBTC is a synergy of U.S. and European stakeholders aimed at developing tools of evidence-based medicine for toxicology. Dr Hartung stated that Tox21, the Human Toxome project, and the EBTC could provide a credible approach to build upon new knowledge and techniques to revamp regulatory toxicology.

Dr Catherine Willett (The Humane Society of the United States), in a presentation titled "The Future of Endocrine Screening: An Animal Welfare Perspective", described the current two-tiered structure of the EPA's EDSP as resource-, labor-, and animal-intensive. She noted that the eleven Tier 1 screens currently use more than 500 animals per assessment (not including a range-finding study), with several thousand more (in multiple species) required for future Tier 2 testing. She described a number of issues with the current approach, including: 1) insufficient opportunity for chemically-relevant tailoring of specific studies or the battery; 2) the generation of large amounts of data, only some of which is applicable for regulatory use; 3) a lack of predictivity; and 4) coverage of only a subset of endocrine effects. Dr Willett proposed a multi-tiered approach, similar to the Endocrine Disrupter Testing and Assessment (EDTA) Framework of the $\mathrm{OECD}^{6}$ to improve the current EDSP structure (Willett et al., 2011). The proposed system would enable increased opportunities for chemical specific assessment by sequentially evaluating: 1) all existing information (e.g., physiochemical); 2) potential MOA; 3) tests for potential effects in complex systems or multiple MOA; and 4) assays measuring adverse outcomes and dose-response. She noted that the adoption of such a structure could allow the incorporation of new methods and assessment tools as they are developed, including the screening tools offered by EPA's CompTox and ToxCast ${ }^{\mathrm{TM}}$ programs that can cover a broader range of doses and biological effects, facilitating the transition from the current Tier 1 assays to the envisioned fully in vitro Tier 1 battery.

Dr Lisa Ortego (Bayer CropScience), in a talk titled "Road Map for Building Scientific Confidence in HTP Assays", outlined a framework approach for a proposed validation strategy that could provide necessary evidence for the acceptance of high-throughput screening (HTS) assays and prediction models for regulatory applications pertaining to endocrine screening and testing. She noted that although HTS assays are generally considered the future of endocrine evaluation, there has yet to be an agreed framework for developing the scientific confidence in these assays and in fact, to date, validation is lagging behind. Recently, Patlewicz et al. (2013) described the Institute of Medicine Biomarker Framework (IOM) and the OECD QSAR Validation Strategy as models that could be adapted to provide guidance on the required validation for HTS assays. Relevant elements of these approaches that are applicable to establishing scientific confidence in HTS assays and prediction models include: 1) a scientific and regulatory purpose for the assay; 2) a detailed protocol including both positive and negative controls; 3 ) the limitations of the assay in relation to reliability and reproducibility; 4) the chemical domain of applicability; and 5) a priori criterion for interpretation and a defined algorithm for predictivity. Dr Ortego pointed out that prediction models should be developed and evaluated using appropriate training sets with data criteria, filters, and algorithms each disseminated to ensure $100 \%$ transparency. Dr Ortego stated that enhanced communication through peerreviewed publications, greater use of independent scientific advisory boards, and systematic collaborative reviews could aid in this proposed validation process.

Dr Thaddeus Schug (NIEHS), in a talk titled "Designing the Next Generation of Sustainable Chemicals", outlined an endocrine disruption testing protocol to be utilized by chemists in the design of new chemicals (Schug et al., 2013). A central goal of green chemistry is to identify potential hazards during the design of new chemicals. Dr Schug's perspective was that endocrine disruption is a type of hazard that has been inadequately addressed by both those developing new chemistries and regulatory bodies. He noted that the proposed protocol, termed "The Tiered Protocol for Endocrine Disruption (TiPED)", was created under the oversight of a scientific advisory committee composed of representatives from both green chemistry and environmental health sciences. It consists of a five-tiered testing system and includes: 1) broad in silico evaluation; 2) high-throughput cellbased screening assays; and 3) whole organism based assays. In addition, the fluid nature of the protocol allows for the incorporation of new, modernized assays as the science advances. Dr Schug stated that this voluntary testing protocol could be a dynamic tool to facilitate the efficient and early identification of potentially problematic chemicals, thus reducing potential risks to public health (Birnbaum, 2013).

\section{Sessions III and IV: Open discussions}

The Session III speakers formed a panel and engaged the participants in a question and answer period following their presentations. This allowed the speakers to interact with the attendees and provide perspective on how the future of EDSP may be shaped by the integration of Tox 21 initiatives and approaches. In Session IV all workshop attendees were provided a final, extended opportunity to share their experiences, perspectives, and concerns regarding the current and future components of the EDSP.

The Session IV discussion period was preceded by Dr James Lamb (Exponent Inc.) who provided some comments to help focus the participants' remarks to the previously highlighted issues from the plenary talks and earlier discussions. He noted that the EDSP Tier 1 battery is currently a valuable strategy for screening chemicals and it would be impractical to ignore these assays going forward. He stated that the strategy could be reevaluated upon future validation of ToxCast ${ }^{\mathrm{TM}}$; however, at the

\footnotetext{
5 http://www.ebtox.com

6 http://bit.ly/1hVnn6T
} 
present time it is impossible to ignore physiological systems, and that MOA information alone can lead to further studies useful in the prediction or prevention of adverse effects. Dr Lamb also highlighted several other important issues including: 1) the need for continued modernization of methods; 2) the need for improving the conduct of range-finding studies; 3) associated study design issues for selected assays (i.e., inability to obtain spermatogenesis information from an immature male); and, 4) the consideration of an organized WOE assessment approach to match data with potency.

The workshop discussion sessions were far-ranging and were not restricted to specific topics. Although the discussions did not occur in any particular order, several common themes emerged during the discussion, and these themes are used below to present a summary of the discussions and recommendations.

\subsection{High Throughput Screening and alternative methods}

Participants envisioned that HTS assays and adverse outcome pathways could be applicable to both mammalian and nonmammalian animal models. It was noted that the EPA is funding grants directed towards the development of adverse outcome pathways and endocrine assays in fish and invertebrate models. Similar studies are currently being conducted in the EPA ToxCast $^{\mathrm{TM}}$ (ToxCast 1.2) with a subset of Tox 21 chemicals in C. elegans ${ }^{7}$.

A participant suggested that a more focused, hypothesisdriven approach to toxicology could aid in future acceptance of in vitro HTS assays examining molecular pathways of toxicity. The ability, or lack thereof, of HTS approaches and in vitro assay systems to account for metabolism was noted and as such these assays intrinsically only investigate the parent compound. Therefore, it was postulated that the "true exposure" to the active agent (i.e., the active metabolite) could be missed. A critical understanding and knowledge of the distribution of chemicals and how in vitro testing assays relate to in vivo target systems would be required. It was noted that enhanced predictive tools and stringent validation practices would be necessary to achieve future regulatory acceptance of molecular pathways for toxicity testing, as well as for hazard and risk assessments.

Some participants commented positively on the transparency of the EPA ToxCast ${ }^{\mathrm{TM}}$ program, but noted that increased clarity on the types of methods utilized in the program would be beneficial. One attendee voiced concerns over the ability of the ToxCast $^{\mathrm{TM}}$ program to ultimately predict adverse effects/outcomes and hazards, noting that the anticipated timeline for the introduction of a fully mechanistic approach for toxicity testing is still some decades away. Others mentioned that making the data generated by ToxCast ${ }^{\mathrm{TM}}$, EDSP, and other related programs publicly available would be beneficial to advance the development of new and improved methods (and validation of prediction models). One person mentioned that the EPA has been amenable and actively interested in discussing various potential approaches the EPA is considering for use in modern toxicity testing with registrants and others.
Participants commented that the development, validation, and implementation of modernized alternative methods that reduce, refine, and replace the use of animals should be a goal of the screening and testing program. Improved venues for stakeholder engagement on EDSP HTS approaches with the EPA were suggested in order to advance the development and application of such methods into the EDSP. In addition, it was suggested that the participation by EPA and stakeholders in the OECD activities on adverse outcome pathways and Integrated Approaches to Testing and Assessment (IATA) would be an important means to promote sharing of lessons learned and help catalyze transition from conventional testing to Tox 21 based approaches over time as the science evolves and as experience is gained.

\subsection{Utilization of exposure information}

The attendees discussed that explicit consideration of human and ecological exposure potential could be valuable to aid in prioritization for the EDSP. A number of participants commented that they were pleased to learn that current research collaborations (e.g., EPA ExpoCast, Hamner Institutes) are being focused at improving exposure assessment and reverse dosimetry screening of high-throughput assays (i.e., Wetmore et al., 2012). These types of efforts show promise for use in priority setting and ultimately for screening-level safety assessment purposes. Some participants emphasized that the prioritization of such large numbers of chemicals requires some quantitative assessment of exposure and possibly additional tools for use in evaluating the large numbers of chemicals in EPA's proposed EDSP universe. Exposure information is needed to facilitate risk-based decision making and could be used to assign lower priority for additional EDSP screening or testing where exposure is minimal or there is a greater margin between exposure and effect levels.

A number of attendees discussed consideration of available information on human biomonitoring data and thought this essential to enable better-informed testing going forward. It was noted that human biomonitoring levels for several hundred chemicals are already available and extensive work has been published on approaches that enable human biomonitoring data to be interpreted in a risk context (Aylward et al., 2013; Wambaugh et al., 2013). Workshop participants noted that the implementation and use of biomonitoring/exposure (i.e., internal dose) could provide greater understanding and a better means to compare the significance of concentrations responsible for exerting effects in vitro with respect to the internal doses that produce responses in in vivo studies.

Several participants stated that the EPA recognizes the importance of chemical "use" data submitted to EPA under the EDSP. However, it was noted that while summary results can be communicated by EPA, dissemination of the detailed data may be limited by proprietary restrictions.

\subsection{Other issues}

Looking more broadly at toxicology and risk assessment issues - beyond Tier 1 screening and the EDSP - several individuals identified and discussed a number of specific opportunities and/

\footnotetext{
7 http://www.epa.gov/pesticides/ppdc/testing/feb09/toxcast-presentation.pdf
} 
or challenges for the future, including the necessity of developing a "common language" and systematic approach for the discussion of mechanistic pathways. Others mentioned that an issue for current and future evidence-based toxicological approaches is the appropriate utilization of all available information for determining probabilistic risk assessment processes. The condensation of available information into an appropriate, manageable structure represents an ongoing significant challenge.

An attendee was concerned that a positive EDSP screening might result in companies substituting other chemicals that might have other toxicities. Other participants noted that many companies already have established strategies (e.g., battery or tiered approaches) early in their new chemical developmental process to avoid this potential.

Several participants questioned the relative impact of the EDSP on the European classification program, which is not risk based. In particular, concern was expressed that European regulatory authorities might consider the results of the EDSP Tier 1 screening studies sufficient to classify chemicals and support recommendation for specific chemical bans even though risk assessment is not the purpose of Tier 1 screening.

\subsection{Improving the EDSP}

The need for a critical review and update of current EPA EDSP Tier 1 test guidelines, with a focus on improving test method procedures to enhance data quality and/or relevance, was suggested. It was noted that, based on the experience gained with the first set of 52 substances, several current EPA guidelines have serious shortcomings and may be outdated and/or superseded by more recent improved methods or procedures. Recognizing that the EPA is aware of this issue, workshop participants thought it prudent that current EPA 890-series test guidelines be appropriately revised prior to requiring further screening of additional chemicals. The need for a guideline detailing a definitive approach to dose setting was discussed and supported by several of those who spoke, who noted that this would be particularly useful for those Tier 1 screens that have current technical challenges.

Some participants thought that a robust WOE approach could align available Tier 1 data with potency and exposure information to better inform decisions about what, if any, specific additional Tier 2 testing would be warranted. Several participants spoke favorably about the proposed logic-based decision-tree strategy that could tailor EDSP Tier 2 testing. It was suggested that stakeholder groups could design structured case studies around specific screens in order to determine which would be conducted, as well as the content/data that would be generated.

The ensuing discussion raised the question of whether additional EDSP Tier 1 screening should be put on hold for a year or so while the current battery of Tier 1 screens (and the assessment process for WOE) is evaluated and improved. Additional discussion centered on the proposed two-assay "gatekeeper" approach (e.g., Tier 0.5) as a possible improvement to the staging and conduct of the current EDSP Tier 1 battery. Numerous participants commented that they thought the "gatekeeper" approach represents a useful and practical proposal that could more rapidly and cost-effectively differentiate substances with little to no significant EAT activity from substances with positive EAT activity; additional screening could then be focused on the subset with positive activity. Some suggested that the EPA allow stakeholders to start future EDSP screening with just these two in vivo assays, with chemicals yielding negative results placed into a "HOLD" box with no further EDSP screening required, and those with positive response subjected to the specific additional Tier 1 assays indicated by the specific EAT endpoint responses observed.

Participants agreed that collaboration, coordination, and communication amongst the regulatory community and stakeholders is vital to ensure continued progress in development and application of HTS assays and computational profiling prediction models for improving both the EDSP and understanding of a chemical's potential for influencing endocrine activity.

\section{References}

Ankley, G. T. and Gray, L. E. (2013). Cross-species conservation of endocrine pathways: A critical analysis of tier 1 fish and rat screening assays with 12 model chemicals. Environ Toxicol Chem 32, 1084-1087.

Aylward, L. L., Kirman, C. R., Schoeny, R., et al. (2013). Evaluation of biomonitoring data from the CDC National exposure report in a risk assessment context: perspectives across chemicals. Environ Health Perspect 121, 287-294.

Bhattacharya, S., Zhang, Q., Carmichael, P. C., et al. (2011). Toxicity testing in the $21^{\text {st }}$ century: Defining new risk assessment approaches based on perturbation of intracellular toxicity pathways using the p53 DNA-damage and repair pathway as a prototype. PLoS One 6, e20887.

Birnbaum, L. S. (2013). Designing safer chemicals. Environ Health Perspect 121, a9.

Blystone, C. R., Kissling, G. E., Bishop, J. B., et al. (2010). Determination of the di-(2-ethylhexyl) phthalate NOAEL for reproductive development in the rat: importance of the retention of extra animals to adulthood. Toxicol Sci 116, 640-646.

Borgert, C. J., Mihaich, E. M., Ortego, L. S., et al. (2011a). Hypothesis-driven weight of evidence framework for evaluating data within the U.S. EPA's Endocrine Disruptor Screening Program. Regul Toxicol Pharmacol 61, 185-191.

Borgert, C. J., Mihaich, E. M., Quill, T. F., et al. (2011b). Evaluation of EPA's tier 1 endocrine screening battery and recommendations for improving the interpretation of screening results. Regul Toxicol Pharmacol 59, 397-411.

Borgert, C. J., Stuchal, L. D., Mihaich, E. M., et al. (2013). Relevance weighting of Tier 1 EDSP endpoints by rank ordering, in preparation.

Freyberger, A., Ellinger-Ziegelbauer, H., and Krötlinger, F. (2007). Evaluation of the rodent Hershberger bioassay: testing of coded chemicals and supplementary molecular-biological and biochemical investigations. Toxicology 239, 77-88.

Laws, S. C., Yavanhxay, S., Cooper, R. L., et al. (2006). Nature of the binding interaction for 50 structurally diverse chemicals with rat estrogen receptors. Toxicol Sci 94, 46-56.

Laws, S. C., Stoker, T. E., Ferrell, J. M., et al. (2007). Effects of altered food intake during pubertal development in male and 
female Wistar rats. Toxicol Sci 100, 194-202.

Marty, M. S. (2013). Mammalian methods for detecting and assessing endocrine-active compounds. In P. Matthiessen (ed.), Endocrine Disruptors. Hazard Testing and Assessment Methods (304-340). Hoboken, New Jersey, USA: John Wiley and Sons, Inc..

NRC - National Research Council (2007). Toxicity Testing in the $21^{\text {st }}$ Century: A Vision and a Strategy. Washington, DC, USA: The National Academies Press.

OECD - Organisation for Economic Cooperation and Development (2012). OECD Guideline for the Testing of Chemicals 443: Extended One-Generation Reproductive Toxicity Study. Paris. Organisation for Economic Co-operation and Development.

Patlewicz, G., Simon, T., Goyak, K., et al. (2013). Use and validation of HT/HC assays to support $21^{\text {st }}$ century toxicity evaluations. Regul Toxicol Pharmacol 65, 259-268.

Schug, T. T., Abagyan, R., Blumberg, B., et al. (2013). Designing endocrine disruption out of the next generation of chemicals. Green Chemistry 15, 181-198.

U.S. EPA - U.S. Environmental Protection Agency (1996a). Food Quality Protection Act. Public Law 104-170, $104^{\text {th }}$ Congress. http://www.epa.gov/endo/pubs/edspoverview/ chronology.htm

U.S. EPA (1996b). Safe Drinking Water Act. Amendment. Public Law. http://www.epa.gov/lawsregs/rulesregs/sdwa/index.cfm

U.S. EPA (2005). Guidance for thyroid assays in pregnant animals, fetuses and postnatal animals, and adult animals. Office of Pesticide Programs, Washington, D.C., October 24, 2005.

U.S. EPA (2011a). Endocrine Disruptor Screening Program for the $21^{\text {st }}$ Century: (EDSP21 Work Plan) The incorporation of in silico models and in vitro high throughput assays in the endocrine disruptor screening program (EDSP) for prioritization and screening. September 30, 2011. http://www.epa.gov/endo/pubs/ edsp21_work_plan_summary\%20_overview_final.pdf

U.S. EPA (2011b). Endocrine Disruptor Screening Program. Weight-of-Evidence: Evaluating Results of EDSPTier 1 Screening to Identify the Need for Tier 2 Testing. September 14, 2011. http://www.regulations.gov/\#!documentDetail;D=EPA-HQOPPT-2010-0877-0021

U.S. EPA (2012). Endocrine Disruptor Screening Program: Universe of Chemicals and General Validation Principles. November 2012. http://www.epa.gov/endo/pubs/edsp_chemical_universe_and_general_validations_white_paper_11_12.pdf

U.S. EPA (2013). Information Collection Request (ICR): ICR Addendum for the Second List of Chemicals; Tier 1 Screening of Certain Chemicals Under the Endocrine Disruptor Screening Program (EDSP); EPA ICR No. 2488.01, OMB Control No. 2070. Attachment F: Calculations for Paperwork Burden and Costs for Data Generation Activities. April, 2013. http://www. regulations.gov/\#! docketDetail;D=EPA-HQ-OPPT-2013-0275

Wambaugh, J. F., Setzer, R. W., Reif, D. M., et al. (2013). Highthroughput models for exposure-based chemical prioritiziation in the ExpoCast Project. Environ Sci Technol 47, 8479-8488.

Wetmore, B.A.,Wambaugh, J. F., Ferguson, S. S., et al. (2012). Integration of dosimetry, exposure, and high-throughput screening data in chemical toxicity assessment. Toxicol Sci 125, 157-174.
Willett, C., Bishop, P., and Sullivan, K. (2011). Application of an integrated testing strategy to the U.S. EPA endocrine disruptor screening program. Toxicol Sci 123, 15-25.

\section{Acknowledgements}

The authors wish to thank Dr David Dix of the EPA for his contributions. The Organizing Committee is grateful to the organizations listed below that made the workshop possible through their generous monetary and in-kind contributions.

\begin{tabular}{|c|c|}
\hline - ABC Laboratories, Inc. & $\begin{array}{l}\text { - Huntingdon Life Sciences/ } \\
\text { LSR Associates }\end{array}$ \\
\hline Research Council & - Human Toxicology Project \\
\hline - Alliance for Risk Assessment & Consortium \\
\hline - American Chemistry Council & $\begin{array}{l}\text { - The Humane Society of the } \\
\text { United States }\end{array}$ \\
\hline - American Petroleum Institute & $\begin{array}{l}\text { - Integrated Laboratory } \\
\text { Systems, Inc. }\end{array}$ \\
\hline $\begin{array}{l}\text { - AMVAC Chemical } \\
\text { Corporation }\end{array}$ & $\begin{array}{l}\text { - Makhteshim Agan of North } \\
\text { America, Inc. }\end{array}$ \\
\hline - BASF Corporation & - Monsanto \\
\hline - Battelle & - MTBE Consortium \\
\hline - Bayer CropScience & - North Carolina Biotechnology \\
\hline $\begin{array}{l}\text { - Center for Alternatives to } \\
\text { Animal Testing (CAAT/Johns } \\
\text { Hopkins) }\end{array}$ & $\begin{array}{l}\text { Center } \\
\text { - Personal Care Products } \\
\text { Council }\end{array}$ \\
\hline - CeeTox, Inc. & - Smithers Viscient \\
\hline - Chem & - Society of Chemical \\
\hline $\begin{array}{l}\text { - Council of Producers } \\
\text { \& Distributors of }\end{array}$ & $\begin{array}{l}\text { Manufacturers and Affiliates, } \\
\text { Inc. }\end{array}$ \\
\hline $\begin{array}{l}\text { Agrotechnology } \\
\text { - Consumer Specialty Products }\end{array}$ & $\begin{array}{l}\text { - Styrene Information and } \\
\text { Research Council }\end{array}$ \\
\hline Association & - Society of Toxicology \\
\hline - CropLife America & - SOT Regulatory Safety \\
\hline $\begin{array}{l}\text { - Doerenkamp-Zbinden } \\
\text { Foundation }\end{array}$ & $\begin{array}{l}\text { Evaluation Specialty Section } \\
\text { (RSESS) }\end{array}$ \\
\hline - Dow AgroSciences & - SOT Ethical, Legal and Social \\
\hline - DuPont & Issue Specialty Group (ELSI) \\
\hline - Endocrine Policy Forum & - Syngenta \\
\hline $\begin{array}{l}\text { - ExxonMobil Biomedical } \\
\text { Sciences, Inc. }\end{array}$ & $\begin{array}{r}\text { - Toxicology Excellence for } \\
\text { Risk Assessment (TERA) }\end{array}$ \\
\hline $\begin{array}{l}\text { - Grocery Manufacturers } \\
\text { Association }\end{array}$ & $\begin{array}{l}\text { - WIL Research } \\
\text { - Wildlife International }\end{array}$ \\
\hline - Gowan & \\
\hline
\end{tabular}

\section{Correspondence to}

Daland R. Juberg, PhD, ATS

Dow AgroSciences LLC

9330 Zionsville Road

Indianapolis, IN 46268

USA

Phone: +1 3173373787

e-mail: drjuberg@dow.com 